\title{
IMPACT OF FASTER FREIGHT TRAINS ON RAILWAY CAPACITY AND OPERATIONAL QUALITY
}

\author{
JAKOB GEISCHBERGER \& MICHAEL MOENSTERS \\ Institute of Transportation Systems (TS), Germany
}

\begin{abstract}
In view of the transition towards climate-friendly transportation, mobility and freight traffic demand are both expected to grow in Europe's already heavily occupied railway networks. To accommodate the increasing traffic volume, capacity-optimised traffic planning is a requirement. One key factor in this context is the heterogeneity of train speeds on heavily used mixed-traffic railway lines. In this paper, we study the effects of train speed harmonisation based on the increase of freight train velocities. Two planning scenarios are addressed: in the first case, freight trains have a conventional speed profile but can occasionally make use of their higher allowed speed level when needed. This can be used in operations to recover from delays or blend in with passenger traffic. In the second case, freight trains are scheduled to so-called 'express train paths' - reaching a more homogeneous timetable profile. The two planning concepts are analysed and compared in a microscopic simulation approach. It is shown that scenarios based on the first planning concept tend to have positive effects on operational quality and capacity, whereas scenarios using 'express freight train paths' are less promising in this respect.

Keywords: express freight trains, microscopic simulation, punctuality, railway capacity.
\end{abstract}

\section{INTRODUCTION}

The importance of rail freight for the transport sector is expected to continue growing within the next years [1]. Not least the discussion about climate-friendliness of different modes of transport attracts public attention and discussion to rail transport. The constantly growing rail passenger traffic volumes confirm this trend [2].

This higher demand leads to a higher occupation of railway infrastructure and consequently results in the question whether the existing track capacity is sufficient in this respect. Especially some of the heavily occupied corridors of nationwide importance are overloaded and hence capacity is not sufficient there [3]. For this reason the European Union has formulated objectives within the Shift2Rail framework that include, amongst others, doubling railway capacity [4].

Existing railway capacity can be increased by different measures. Suggestions include technical innovations of both infrastructure and trains, the expansion of infrastructure or changes in operations. In the context of the latter, the harmonisation of timetables and thus speeds is discussed [5]. Thereby, the speed levels of different train categories are aligned in order to make train operations as 'smooth' as possible by reducing minimum headway times and avoiding overtakings. This leads to a higher capacity in a certain line segment. Ultimately, at mixed-traffic lines, harmonisation of speeds always means an acceleration or deceleration of certain trains or train categories.

Only few studies address the possibility of speeding up freight trains in order to harmonise the speed of trains. Hence, this paper deals with the impact of faster freight trains on operational quality and railway capacity. A distinction into two cases was made to clarify the approach: 
A) Freight trains can occasionally make use of their allowed higher speed level only when needed. This leads to higher recovery margins. The resulting higher flexibility can be used in operations to recover from delays or blend in with passenger traffic. Apart from this, they operate with conventional timetables and speed profiles.

B) Freight trains are scheduled to so-called 'express train paths' - reaching a more homogeneous timetable profile. This means they are strictly obliged to run faster than with conventional timetables.

This distinction results from a different motivation behind the cases respectively: While in case A) the focus lays on 'smooth' operations with a high flexibility in order to recover from delays or avoid overtakings, case B) strongly focuses on the harmonisation of speeds and both transport time and speed. So while case A) ultimately results in significantly higher recovery margins of the trains, these stay the same in case B). It must be examined as to whether positive effects (such as harmonisation of speeds with long distance passenger trains) or negative effects (conflicts with regional passenger trains) outweigh one another in terms of resulting capacity.

The impact on operational quality as well as capacity of the described cases will be examined further in this paper. For this purpose, basic terms of railway capacity are defined. Moreover, the operation of faster freight trains is addressed in the literature review. This is followed by an explanation of the methodical approach. Afterwards, the results of a performed use case study are presented and discussed in Sections 4 and 5.

\section{LITERATURE}

Theoretical capacity can be referred to as the number of trains that could run over a route during a specific time interval. It defines the upper limit for line capacity [6]. This is complemented by the term of practical capacity, which can be defined, according to UIC code 406, as the number of train paths that can be scheduled with market-oriented quality [7]. Thus practical capacity is influenced by a desired operational quality, often referred to as 'level of service' [8]. A comparison of further definitions of capacity can be found in [9].

Several different methods exist to measure and evaluate railway capacity. This includes constructive methods, concatenation according to UIC code 406, as well as simulations and analytical approaches. These methods all have both advantages and disadvantages with respect to output parameters, processing efforts, independence from timetables or how close the models are to real-life train operations. It is not uncommon to pursue an approach with multiple methods, as for example in [10] or [11], because the different methods can lead to different results. Therefore, a comparison between two or more methods can be helpful [11].

In addition to the number of trains or traffic load, the heterogeneity of trains and train categories has a strong influence on capacity as well [12]. Different train categories (and thus speed levels) are referred to as mixed-traffic. Mixed-traffic results in longer headway times and thus has negative effects on capacity. This contrasts to homogenous train operations typical for commuter rail systems, where a strong harmonisation of speeds is observed, such that small minimum headway times and dense train sequences can be accomplished. Unmixing of trains in both a spatial and temporal dimension can lead to stronger harmonisation and have been introduced in [12] as means to increase capacity. In addition, it is argued that the alignment of speed levels is of special importance in bottleneck segments. Further confirmation in this respect can be found for example in [13]. Moreover, several studies and publications deal with this topic, as in [5], [11] or [14]. Corresponding studies for the German rail system can be found in [15], [16] or [17].

Faster freight trains were part of several former and current operational concepts. However, many of these have been discontinued, mostly due to the lack of profitability or demand. 
Moreover, some of the concepts could not avoid conventional freight trains being further disadvantaged. A list can be found in [18]. Faster freight trains were also analysed in [19], where the focus is on potential markets for faster freight trains. However, the potential conflicts with other, slower trains are mentioned.

Higher speed levels entail rising requirements in terms of both equipment and driving dynamics of the trains and especially their wagons. Current freight train wagons with a maximum speed of up to $120 \mathrm{~km} / \mathrm{h}$ need additional equipment to raise this level above $140 \mathrm{~km} / \mathrm{h}$ and up to $160 \mathrm{~km} / \mathrm{h}$. This includes, amongst others, disc brakes, electro-pneumatic brakes, a self-adjusting load-proportional braking system, a brake pipe accelerator, wheel slide protection and a higher braking regime. This, of course, means significant investments in order to reach higher speed levels. The operation of faster freight trains up to $140 \mathrm{~km} / \mathrm{h}$, however, seems to go along with comparably small investments [18, 20,21]. This paper focusses, however, rather on operational implications than technical feasibility.

\section{METHODICAL APPROACH}

In this paper, we deal with a research question that has a strong link to real-life train operations, especially with respect to case A) which focusses on operational flexibility. To analyse the effect of a permitted, but not necessarily actualised higher allowed speed, a microscopic simulation is chosen and performed. Unlike asynchronous methods it can model and analyse the performance of a rail corridor in an operational setting. Hence, it is highly suitable to model railway operations closely linked to real circumstances and a specific timetable in order to measure the change of delays within a certain line. The detailed implementation of particular trains, infrastructure as well as control-command and signalling can be pointed out as another reason.

Thus, a microscopic simulation model was created using the railway operations simulation software RailSys ${ }^{\circledR}$. A heavily occupied mixed-traffic line with a high number of freight trains was chosen to be implemented, as the analysis should evaluate the effects in circumstances where demand of additional trains is high. The model is based on nodes and edges and includes several other layers of infrastructure including control-command and signalling. Operating locations including major junction stations were implemented on the detail level of tracks and switches. Timetables for both freight and passenger trains were imported from publicly accessible sources for a time span of $24 \mathrm{~h}$ (simulation period). The evaluation period was defined from 6 am to $10 \mathrm{pm}$ (in order to allow the simulation to settle before evaluation starts). It can be justified by higher line occupation during the daytime. A distribution of entry delays was applied to all trains entering the system: while long distance trains have an average delay of $5 \mathrm{~min}$ with a probability of 0.5 , regional trains have an average delay of $4.5 \mathrm{~min}$ with a probability of 0.6 . Freight trains delay by an average $10 \mathrm{~min}$ with a probability of 0.6 . These parameters were chosen according to Deutsche Bahn Guideline 405 [22].

As mentioned in Section 1, the recovery margin has significant influence on operational quality, because the parameter represents the ability of a delayed train to reduce its delay while running through the system (independently of its maximum speed). Recovery margins were defined according to Deutsche Bahn Guideline 402 [23].

The difference in delays was chosen as evaluation parameter. It is an indicator of operational quality [24]. It can be calculated by the difference between exit and entry delay and therefore represents the behaviour of delay of a certain train within a system. In this context, Heister [25] differentiates between three possible states of the evaluation parameter (as shown in Table 1). 
Table 1: States of the difference in delays (according to Heister [25]).

\begin{tabular}{|c|c|c|}
\hline Behaviour & Difference in delays & Conclusion \\
\hline $\begin{array}{l}\text { The delay of a train } \\
\text { increases when running } \\
\text { through the system }\end{array}$ & Positive & $\begin{array}{l}\text { The system is overloaded. In order to im- } \\
\text { prove defective operational quality, the } \\
\text { number of trains may have to be reduced }\end{array}$ \\
\hline $\begin{array}{l}\text { The delay of a train } \\
\text { does neither increase } \\
\text { nor decrease when run- } \\
\text { ning through the system }\end{array}$ & 0 & The operational quality is 'satisfactory' \\
\hline $\begin{array}{l}\text { The delay of a train } \\
\text { decreases when running } \\
\text { through the system }\end{array}$ & Negative & $\begin{array}{l}\text { The system allows reduction of delays } \\
\text { while maintaining good operational } \\
\text { quality. Under some circumstances, ad- } \\
\text { ditional trains could be added }\end{array}$ \\
\hline
\end{tabular}

Both entry and exit delay were measured at the stop board of the first and last stop of a train respectively. This has to be distinguished from measuring at the entry and exit point directly. The latter might lead to falsified results due to entry dispatching algorithms in RailSys. Moreover, the behaviour of the trains within the junction stations should be included in the analysis as well.

The dispatching routine and configuration in an operational simulation model affects results considerably. It is bound to several parameters, one of them being the dispatching priority. In case of a conflict of trains, this value decides which train to prioritise and which one to hold back or stop. In real-life operations, normally higher priority is given to passenger trains than to freight trains, as in many countries passenger traffic operates in tight, aligned intervals in order to enable comfortable and quick interchanges. This was not changed in the context of this study.

The correlation between operational quality and the capacity of a line was methodically implemented as follows: a reference timetable was systematically enriched with additional freight train paths. This was performed by the enrichment function according to UIC code 406, which is part of the RailSys functionality. Enriching a timetable with additional paths leads to a higher number of freight trains. Therefore, operational quality deteriorates. The enrichment process was continued as long as there was still space for additional paths in the analysed time table (hereby, a rather theoretical buffer time of $30 \mathrm{~s}$ is upheld). When enriching timetables according to UIC code 406 the stop criterion must be that no more free space for additional paths is left within the timetable (other stop criteria exist and might be reached even though free space is still available). For this reason the enrichment process as used in this paper is rather about determining a system's theoretical load maximum than calculating practically performable timetables. For both the reference and the fully enriched timetable, the difference in delays was measured via simulation. Afterwards, starting with the fully enriched timetable, additional trains were step by step removed again while constantly measuring the difference in delays for each step. This was conducted until the removal process ends with the reference timetable again. This results in a curve where differences in delays can be plotted over the number of additional trains. The difference in delays is expected to rise when raising the number of additional trains.

The described methodical approach is now applied to several scenarios as shown in Table 2. 
Table 2: Scenarios.

\begin{tabular}{llll}
\hline Scenario & Name & $\begin{array}{l}\text { Allowed maximum speed } \\
\text { of freight trains }(\mathrm{km} / \mathrm{h})\end{array}$ & $\begin{array}{l}\text { Case } \\
(\text { cf. section 1) }\end{array}$ \\
\hline Scenario 1 & Reference timetable (RTT) $^{\text {conventional }(100)}$ & Reference case \\
Scenario 2 & RTT v $_{\max } 120$ & 120 & Case A) \\
Scenario 3 & RTT v $_{\max } 140$ & 140 & Case A) \\
Scenario 4 & RTT v $_{\max } 160$ & 160 & Case A) \\
Scenario 5 & ${\text { Express timetable } \mathrm{v}_{\max } 160} 160$ & Case B) \\
\hline
\end{tabular}

We choose five scenarios: scenario 1 is the reference timetable that represents current reallife operations. Scenarios 2, 3 and 4 signify case A) with its higher flexibility. Scenario 5 contains 'express freight train paths' as in case B). The choice of speed levels was motivated as follows: $160 \mathrm{~km} / \mathrm{h}$ is assumed as the maximum speed of the freight trains and hence defines the maximum speed of both analysed cases (represented by scenarios 4 and 5). For one thing, this is the allowed maximum speed of passenger trains with conventional signalling (e.g. German intermittent automatic train-running control). For another thing, this maximum speed level was also given in former faster freight train concepts (see Section 2). Moreover, a speed level of $160 \mathrm{~km} / \mathrm{h}$ exhausts the technical and physical possibilities (see also Section 2). Two more gradations ( 120 and $140 \mathrm{~km} / \mathrm{h}$ ) are added to case A) which might entail significantly lower investments (cf. Section 2). (Case B is not diversified accordingly, as there the harmonisation of speeds should be as high as possible).

All three of the scenarios 2, 3 and 4 keep their original reference timetables when simulated. The only simulation parameter that is changed is the allowed maximum speed of freight trains. Scenarios 2 and 3 do explicitly refrain from improved physical attributes as well as better equipment as needed for operation above $140 \mathrm{~km} / \mathrm{h}$ (cf. Section 2). Only scenario 4 with a maximum speed of $160 \mathrm{~km} / \mathrm{h}$ might mean larger investments are needed (see Section 2).

In contrast, in scenario 5 new express timetables are created for freight trains at an operating speed of $160 \mathrm{~km} / \mathrm{h}$. In addition, improved physical attributes are assumed as follows: the train has a significantly better braking deceleration than conventional trains (upgrade to $0.5 \mathrm{~m} / \mathrm{s}^{2}$ ) and is equipped with ep-brakes. Hence, it shows attributes similar to those of a long distance passenger train like the German ICE train. The driving dynamics were improved in order to reduce the deceleration phases of the train so it can keep its higher speed path more easily.

As a next step, an evaluation criterion is identified to compare the results of different scenarios. The following hypothesis is therefore formulated: A timetable with faster freight trains and hence potentially better operational quality can be enriched with additional train paths as long as the operational quality does not exceed that of the reference scenario. The number of possible additional train paths identified will be an indicator of free usable capacity caused by faster freight trains.

\section{CASE STUDY}

To analyse the impact of faster freight trains on operational quality and capacity the line segment between the German cities of Offenburg and Freiburg was studied as a use case. This densely operated corridor has a maximum speed level of $160 \mathrm{~km} / \mathrm{h}$ and is part of the European 
TEN corridor Rhine-Alps between Rotterdam and Genua, which is of special importance to the trans-European rail freight transport [26]. Moreover, it represents the only double-tracked bottleneck between Karlsruhe and Basel (the rest for the most part has four parallel tracks).

For the traffic scenarios and train types publicly accessible freight train data from the socalled noise-monitoring initiative in Germany, introduced by the Federal Railway Authority [28], was taken for a representative day. The respective train numbers were implemented into the reference timetable in the simulation model. Freight trains were classified into four model train categories: container trains, trains with bulk goods, block trains and trains with mixed goods. These vary in length and total mass. As a result, train operation was modelled more realistically than with only one freight train category. Passenger trains were divided into the German categories ICE (high-speed long distance train), IC (inter-regional long distance train), RE (regional express train), RB (regional train) and S-Bahn (commuter train). Timetables were imported from the digital timetable book of Deutsche Bahn [29].

The stations of Offenburg (including its large freight yard) and Gundelfingen were defined as measuring points for the difference in delays. Gundelfingen has a major junction where

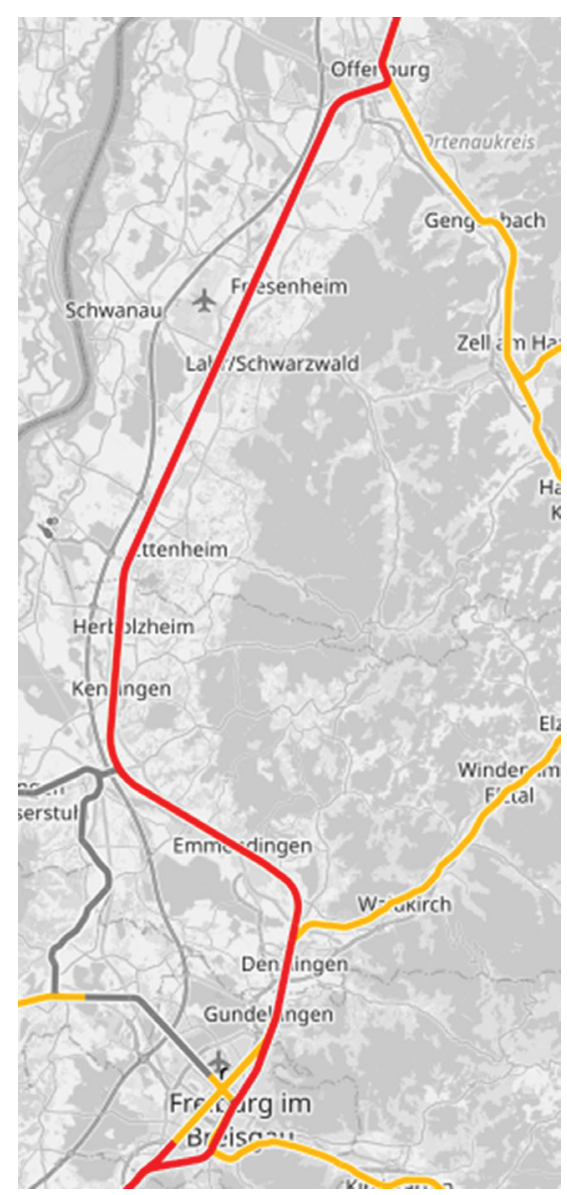

Figure 1: Line segment between Offenburg and Freiburg (Source: Open Railway Map (C) OpenStreetMap-Contributors [27]). 
many freight trains leave the main track and turn to the Freiburg freight train circumvention, while passenger trains stay on the tracks to Freiburg Central Station. For this reason, the total amount of trains in the system significantly changes in Gundelfingen, which is consequently defined as the other border of the system. Figure 1 shows the analysed corridor (in red).

For different scenarios, 100 simulation runs each were performed. This number stems from a trade-off between acceptable running times and at the same time statistically reliable results. However, a slight dispersion of results cannot be ruled out; for this reason they are plotted within a confidence interval.

The reference timetable (i.e. current real-life operations) was simulated by 100 runs and both the recovery margins and distribution of entry delays were implemented as described in Section 3. The resulting differences in delays are calculated by the difference between exit and entry delay (cf. Section 3) and are shown by train categories in Fig. 2.

Figure 2 shows that the difference in delays over all trains is $1.9 \mathrm{~s}$ and thus delay slightly increases. This confirms the high occupation of the analysed line segment. The parameters are average values of both north and south direction. Due to the different flow of goods, amongst others, the total amount of trains can vary between the two directions. This results in slightly different values for the difference in delay when analysing them separately. But because trains of different directions interact with one another - especially at junctions - a joint analysis of both directions seems plausible. Figure 2 also reflects the dispatching routine of the model: Regional trains, for example, are allowed to reduce their hold time at smaller stops in case of delays. This leads to a negative difference in delays: Regional trains can reduce their delay. Moreover, passenger trains (often with tight intervals) are prioritised in the dispatching. This is in accordance with real-time train operations. As a result, delays of freight trains rise when running through the system. Generally, the values are averages of several hundred trains and therefore within the small digits of seconds. This does explicitly not exclude single trains being hindered or overtaken and therefore collecting several minutes of additional delay.

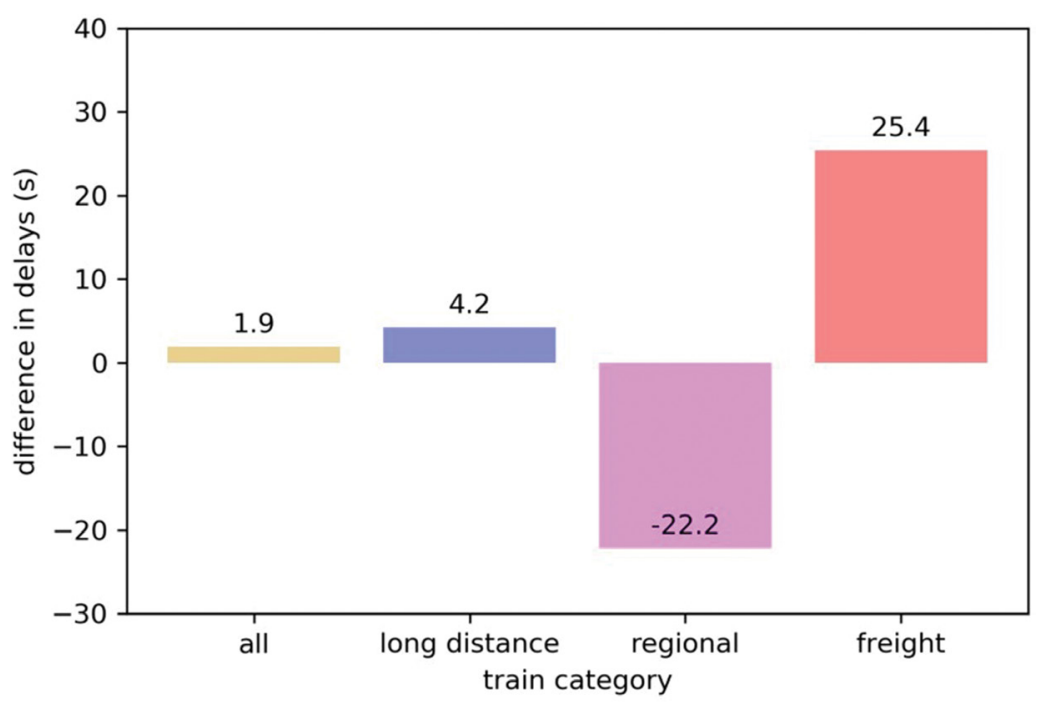

Figure 2: Difference in delays, scenario 1: reference timetable. 
The five scenarios consist of a reference timetable, scenarios 2, 3 and 4 which represent case A) (where trains have significantly higher recovery margins and thus flexibility) and scenario 5 which represents case B) where freight trains are scheduled to 'express paths' (cf. Sections 1 and 3). Figure 3 depicts the results of the simulation of the respective scenarios:

Figure 3 shows the difference in delays of all trains in the respective scenarios on the $y$-axis. The $x$-axis shows the amount of additional freight trains, which were inserted into the respective timetables by the enrichment process described in Section 3. Hence, the $x$-axis represents different timetables where freight trains were inserted step by step (reading from left to right). As described in Section 3, the results were plotted within a confidence interval which is dependent on the standard deviation $\sigma$. A factor of $2 \sigma$ around the data mean value was chosen to determine the width of the shaded area.

We can observe that all curves climb when inserting additional trains. However, only scenarios 2, 3 and 4 (case A)) show a negative difference in delays for most part. Scenario 5 shows an increase in delays - even above the level of scenario 1 . The black horizontal line represents the level of the difference in delays of the reference timetable.

For all scenarios, the rise of difference in delays (and hence deterioration of operational quality) while increasing the number of additional freight trains can be assessed as plausible and represents the expected behaviour. For example, the value of the reference timetable rises by around $5 \mathrm{~s}$ when inserting the maximum number of 30 additional trains.

For scenarios 2, 3 and 4, a significant decrease of delays is observed. This behaviour can be possibly explained by the fact that freight trains are permitted to make use of their higher maximum speed and hence significantly higher recovery margins in order to reduce their delays or avoid being overtaken respectively - their difference in delays decreases. Moreover, long distance trains benefit in the mentioned scenarios, because they are hindered less by preceding freight trains. These effects intensify with higher allowed maximum speed levels of freight trains. All three curves climb when inserting additional trains. It can be observed, that the only curve that reaches the level of operational quality from the reference timetable, is the one of scenario 2 (by intersecting with the horizontal black line). The operational quality

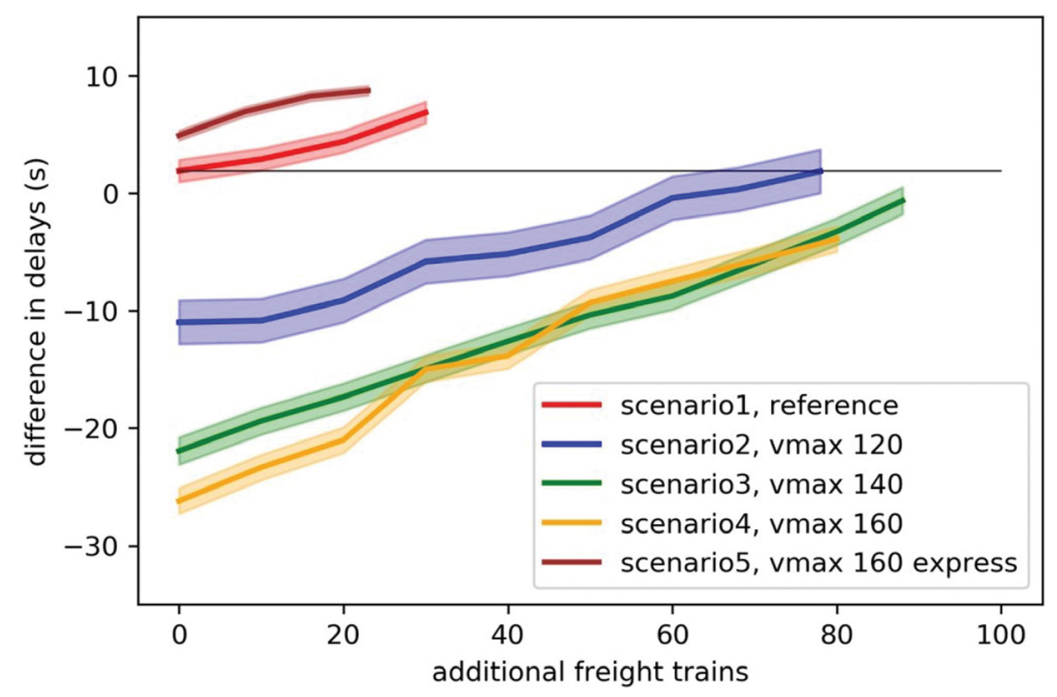

Figure 3: Difference in delays, comparison of scenarios. 

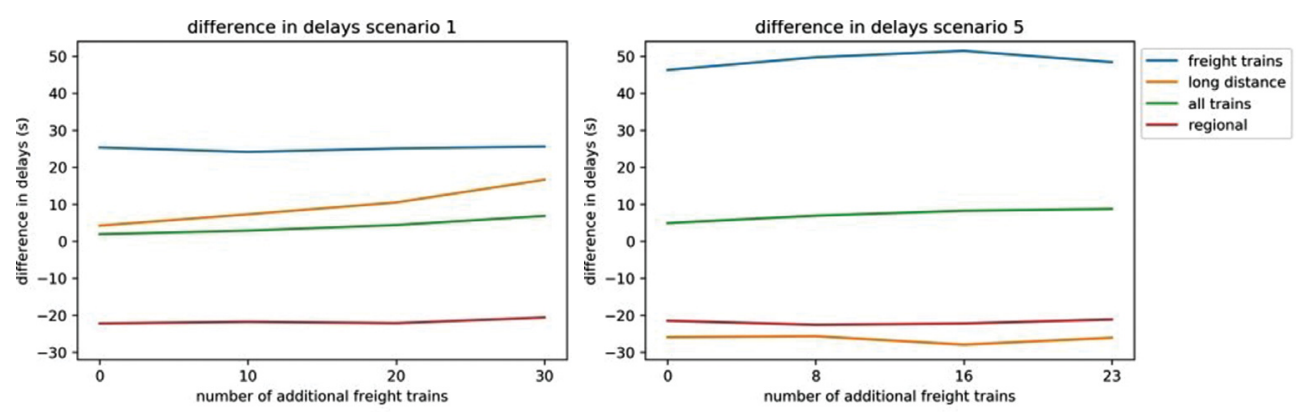

Figure 4: Difference in delays, comparison of scenarios 1 (left) and 5 (right).

of scenarios 3 and 4 does not even reach this level but constantly stays below the described level of the black line - even if the maximum possible amount of additional trains is inserted.

This is in contrast with the behaviour of the curve of scenario 5: There, the level of difference in delays is above the curve of the reference timetable. It slightly climbs when inserting additional trains. It seems that operational quality deteriorates when using express freight train paths under the given circumstances of this case study. The improved driving dynamics do not seem to change this either.

To further analyse the different behaviour of the two traffic planning variants with (Scen. 5) and without (Scens. 1-4) increased scheduled speed the train-specific delay differences are presented in Fig. 4. It shows the difference in delays for both the reference scenario (left) and the express freight train scenario 5 (right). It differentiates between the train categories.

Here, the curve of the long distance trains (orange) is of special importance: While the difference in delays of the long distance trains is only slightly above the average of all trains in scenario 1, it decreases massively in scenario 5 (by approx. 30-40 s). This means that the long distance trains benefit from the faster freight trains and are able to reduce their delay. This is understandable, because in case of a preceding freight train the same will not transfer as much delay to the long distance train behind, as it is running faster itself. The exact opposite can be observed with the freight trains: Paradoxically, they have a disadvantage by their higher allowed maximum speed: Their difference in delays rises by approx. $25 \mathrm{~s}$ (see blue line, comparing from left to right). This can be explained as follows: In case of a preceding slower regional train, a higher amount of additional delay is transferred to the freight train behind than in the reference scenario, because the speed differences are much higher: The set point and actual value of delay differ more strongly. The average over all trains (green line) of scenario 5 is slightly higher than in the reference scenario. This is due to the distribution of train categories: While approx. half of all trains are freight trains, a much smaller part are long distance trains (even smaller than the share of regional trains). For this reason, the case 'long distance train succeeds freight train' will occur more rarely than the case 'freight train succeeds regional train'. Hence, the negative influence explained above outweighs the positive.

\section{DISCUSSION AND FURTHER RESEARCH}

As a result of our study we conclude that on the one hand, it seems that overall operational quality can be enhanced by allowing freight trains a higher maximum speed in case of delay. Hence, the concept described in case A) seems promising. According to the difference in delays of scenario 2, for example, 60-80 additional freight trains could be inserted into both 
directions between 6 am and 10 pm (see Fig. 3). This would mean approx. two additional freight trains per hour and direction. These values are even higher in scenarios 3 and 4, respectively.

Thus, it can be stated that speed homogeneity and the speed of freight trains does indeed have a significant influence on the capacity of mixed-traffic rail corridors. With respect to the seemingly high number of additional freight trains it should, however, be noted that the microscopic simulation performed in this study concentrated on a freight corridor segment of approx. $64 \mathrm{~km}$ length between Offenburg and Freiburg. In reality, the observed capacity could be lower given network-intrinsic constraints arising from the harmonisation of train paths with adjacent line segments. These so-called network effects (see [30]) are not considered in the present study.

Moreover, full migration is assumed (see below) and free capacity might not only be used to insert freight trains. Additionally, better operational quality does not necessarily mean enhanced capacity. Free capacity can also be used to reduce overall delays (see also [4]). Nevertheless, a positive tendency can be observed. Interestingly, the difference between scenarios 2, 3 and 4 is comparably small. This requires further analysis of investments and operational costs that go along with the particular scenarios. Possibly, the scenario with the highest allowed speed level is not necessarily the optimal choice.

On the other hand, faster freight train operations do not seem to bring advantages per se, as the results from scenario 5 show. Accordingly, a strictly raised obligatory maximum speed on express freight train paths slightly deteriorates operational quality. Here the focus of this paper on heavily occupied mixed-traffic lines is of importance. It can be assumed, that express freight trains could make use of their advantages significantly better during night time or in a less occupied infrastructure. Against the background of raising capacity, however, scenario 5 does not seem to be promising. In this context, further research is needed. For example the question arises, in which way results would change if freight trains were given a higher priority. One could argue that a freight train with driving dynamics similar to an ICE train justifies a similar priority as well. It can be assumed that the difference in delays of freight trains (and possibly on average over all trains) would be lower if priorities were changed in this way. This would mean, however, significant operational disadvantages for regional trains. This was not part of the analysis performed here but shows that an isolated analysis of headway times is not sufficient for an overall understanding of capacity.

In addition to the scenarios presented in this paper, a variation of the parameters of the express freight train will be addressed in further research in form of corresponding additional scenarios. It can be assumed that especially the parameter of braking deceleration has significant influence on headway times and thus capacity.

All evaluated scenarios assumed full migration. This means that all freight trains had the characteristics of the particular scenario. Mixed scenarios, where both faster and conventional freight trains operate at the same time, were not analysed and therefore are part of further research to be done. It can be assumed that the positive effects observed in case A) would be reduced. This aspect is closely linked to the demand for faster freight train services. It is hardly conceivable that e.g. heavy-load bulk goods trains operate according to one of the considered scenarios, as their overall mass is too high. Moreover, these sorts of transport do not focus on duration but rather on reliability - the demand for conventional freight trains will remain. It is necessary to rather identify the demand for express freight, such as in the package delivery sector or with non-durable or chilled goods. This, however, is not related to the analysis of capacity. 
Lastly, additional freight trains do not necessarily mean higher overall transport capacity. This results from both physical and regulatory restrictions concerning the operation of faster freight trains. Ultimately, the aim is to raise the amount of goods that can be transported on railway infrastructure and not per se the number of train paths (in this case only short trains were operated). For this reason, further research on the transport capacity of the presented scenarios is required in contrast to other suggestions (such as very long trains).

\section{ACKNOWLEDGEMENTS}

The research performed in this work was part of the framework of the Fr8Hub project. This Shift Rail project has received funding from the Shift2Rail Joint Undertaking under the European Union's Horizon 2020 research and innovation programme under grant agreement No 777402.

\section{REFERENCES}

[1] Bundesministerium für Verkehr und digitale Infrastruktur: Masterplan Schienengüterverkehr, 2017. https://www.bmvi.de/SharedDocs/DE/Publikationen/StV/masterplanschienengueterverkehr.pdf?_blob=publicationFile (Accessed on: 6 May 2020).

[2] European Commission: Report from the Commission to the European Parliament and the Council. Sixth report on monitoring development of the rail market, 2019. https:// ec.europa.eu/transport/sites/transport/files/staff_working_document_6th_rmms_ report.pdf (Accessed on: 14 May 2020).

[3] European Commission: JRC technical reports. Capacity assessment of railway infrastructure, 2016. doi:10.2791/037759 (Accessed on: 14 May 2020).

[4] Shift2Rail: Mission and Objectives. https://shift2rail.org/about-shift2rail/mission-andobjectives/ (Accessed on: 11 May 2020).

[5] Vromans, M. J.: Reliability of railway systems. Trail thesis series, T2005/7. [Delft: Netherlands Trail Research School] op. 2005.

[6] Abril, M., Barber, F., Ingolotti, L., Salido, M. A., Tormos, P. u. Lova, A. An assessment of railway capacity. Transportation Research Part E: Logistics and Transportation Review 44 (2008) 5, S. 774-806.

[7] International Union of Railways: UIC Code 406. [Paris]: UIC, Union Internationale des Chemins de Fer 2004.

[8] Meirich, C. Berechnung und Bewertung der Gesamtleistungsfähigkeit von Eisenbahnnetzen. Veröffentlichungen des Verkehrswissenschaftlichen Institutes der RheinischWestfälischen Technischen Hochschule Aachen, Nr. 69. 2017

[9] Khadem Sameni, M., Landex, A. u. Preston, J. Developing the UIC 406 Method for Capacity Analysis. Proceedings for 4th International Seminar on Railway Operations Research (2011).

[10] UIC: Influence of ETCS on line capacity. Generic study. Paris: ETF, Editions techniques ferroviaires 2008.

[11] Kontaxi, E. u. Ricci, S. Railway capacity analysis: methodological framework and harmonization perspectives. 12th WCTR 2010.

[12] Pachl, J. Systemtechnik des Schienenverkehrs. Bahnbetrieb planen, steuern und sichern; mit zahlreichen Tabellen. 2013.

[13] Schaer, T. Anforderungen an eisenbahnbetriebswissenschaftliche Untersuchungen (EBWU) im Rahmen der Planung und Genehmigung von Eisenbahninfrastrukturprojekten, 2010. http://ifev.rz.tu-bs.de/RailAutomation/RA2010/Internet/3_Schaer.pdf (Accessed on: 6 May 2020). 
[14] Vromans, Michiel J. C. M, Dekker, R. u. Kroon, L. G. Reliability and heterogeneity of railway services. ERIM report series research in management Business processes, logistics and information systems, 2003-090. Rotterdam: ERIM.

[15] Schumann, T. u. Mönsters, M. Energieeinsparung durch Harmonisierung der Geschwindigkeiten im Soll-Fahrplan. EIK (2016), S. 1-15.

[16] Busche, H. u. Schlünß, M. Takt schlägt Tempo - ICE und 'Deutschlandtakt' ein Fehler!? Eisenbahntechnische Rundschau (2017) 11, S. 42-46.

[17] Berschin, F. Hamburg - Hannover. Mehrverkehr wäre schon heute möglich. BahnReport (2009) 06, S. 76-78.

[18] Shift2Rail Fr8Hub: WP3: Real time network management and simulation of increasing speed for freight trains. Deliverable 3.1 State-of-the-art and specification of innovations, demonstrations and simulations. 2018.

[19] Troche, G. High-speed rail freight. Sub-report in efficient train systems for freight transport. Report/KTH Railway Group, Bd. 0512. Stockholm: Järnvägsgruppen, Kungliga tekniska högskolan (KTH) 2005.

[20] dybas: Güterwagen der DB AG. Drehgestell-Containertragwagen. https://www.dybas. de/dybas/gw/gw_s_7/g703.html (Accessed on: 6 May 2020).

[21] Forschungs-Informations-System: InterCargoExpress, 2012. https://www.forschungsinformationssystem.de/servlet/is/402142/ (Accessed on: 6 May 2020).

[22] DB NETZ AG: Richtlinie 405 Fahrwegkapazität. (idF v. 13. 2. 2009).

[23] DB NETZ AG: Richtlinie 402 Trassenmanagement. (idF v. 1. 4. 2006).

[24] Martin, Ullrich.Li, Xiaojun. Nachtigall, Karlin:Anforderungsgerechte Trassenstrukturen und deren Belegung im Netz von Schienenbahnen - Atrans. [S.1.]: books in demand 2020.

[25] Heister, G. Eisenbahnbetriebstechnologie. DB-Fachbuch. Heidelberg u.a.: EisenbahnFachverl 2006.

[26] Bundesministerium für Verkehr und digitale Infrastruktur: Korridormanagement. Rhein Alpen. https://www.bmvi.de/SharedDocs/DE/Artikel/G/transeuropaeische-verkehrsnetzekorridormanagement.html (Accessed on: 5 May 2020).

[27] OpenRailwayMap: map layout: OpenRailwayMap; map data: OpenStreetMap ( OpenStreetMap-Contributors, www.openstreetmap.org/copyright. https://www. openrailwaymap.org/ (Accessed on: 11 May 2020).

[28] Eisenbahn-Bundesamt: Lärm-Monitoring. Schallmessungen im Schienenverkehr. URL https://www.laerm-monitoring.de/zug?mp=16 (Accessed on: 5 May 2020).

[29] Deutsche Bahn AG: Elektronisches Kursbuch. http://kursbuch.bahn.de/hafas/kbview. exe (Accessed on: 5 May 2020).

[30] Landex, A.: Network effects in railways. WIT Press 2012. 